\title{
Protective Effect of Contralateral, Ipsilateral, and Bilateral Remote Ischemic Preconditioning on Spinal Cord Ischemia Reperfusion Injury in Rats
}

\author{
Mojtaba KARIMIPOUR ${ }^{1}$, Gholam Hossein FARJAH ${ }^{2}$, Faranak MOLAZADEH ${ }^{1}$, \\ Mohammad Hasan Khadem ANSARI ${ }^{3}$, Bagher POURHEIDAR ${ }^{1}$ \\ ${ }^{1}$ Urmia University of Medical Sciences, Faculty of Medicine, Department of Anatomy, Urmia, Iran \\ 2Urmia University of Medical Sciences, Faculty of Medicine, Neurophysiology Research Center and Department of Anatomy, Urmia, Iran \\ ${ }^{3}$ Urmia University of Medical Sciences, Faculty of Medicine, Department of Biochemistry, Urmia, Iran
}

Corresponding author: Gholam Hossein FARJAH hfarjah@hotmail.com

\section{ABSTRACT}

AIM: To evaluate the effect of different remote ischemic preconditioning (RIPC) methods in spinal cord ischemia-reperfusion (IR) injury.

MATERIAL and METHODS: A total of 36 rats were distributed to the 6 groups: sham surgery, control (only spinal cord IR), unilateral (hind limb RIPC before spinal cord IR), bilateral (hind limbs RIPC before spinal cord IR), ipsilateral (hind and fore limbs RIPC to the right before spinal cord IR), contralateral (right hind limb and left fore limb as RIPC before spinal cord IR). Thirty minutes after RIPC, the spinal cord was subjected to ischemia for 60 minutes. Seventy two hours after IR, all rats were evaluated by neurological function, histological and biochemical examinations.

RESULTS: The mean Motor Deficit Index (MDI) scores in the ipsilateral, contralateral, and bilateral groups were lower than that of the unilateral group $(p<0.05)$. The mean malondialdehyde (MDA) in ipsilateral group was lower than were control group ( $<<0.05)$. The mean total antioxidant capacity (TAC) and the mean number of normal motor neurons in the experimental groups were significantly higher than increased control group $(p<0.05)$. The mean plasma levels of catalase in the contralateral, ipsilateral, and bilateral groups were significantly increased compared to control group $(\mathrm{p}<0.05)$. The mean scores of white matter damage in contralateral, bilateral, and unilateral groups were lower than control group $(p<0.05)$.

CONCLUSION: The results of this study show that contralateral, ipsilateral, and bilateral limb RIPC may reduce the complications of spinal cord ischemic injury.

KEYWORDS: Contralateral, Ipsilateral, Remote ischemic preconditioning, Spinal cord injury, Rat

\section{INTRODUCTION}

$\mathrm{S}$ urgery on the descending aorta is one of the most common reasons of paraplegia caused by spinal cord ischemiareperfusion (IR) (20). In recent years, new surgical methods and pharmacological factors such as lutein (16), and free radical scavengers (5) reduced the risk of paraplegic in these patients (25). However, despite the therapeutic advancement, sensory and functional complication are observed in these patients. The critical ischemic duration depends on the tissue and organ. For example, in the brain tissue, ischemia of more than 5 minutes causes the death of neuron (19). On the other hand, reperfusion may cause parenchymal and endothelial lesion (23). 
Ischemic Preconditioning (IPC) is a method that a short cycle of ischemia and reperfusion occurs before a long-term ischemia (1). Unfortunately, the implementation of this idea is not possible in vital organs such as the brain and spinal cord (24). Recent studies have shown that IPC may have a protective effect on distant organs and tissues, such as kidney and heart (1). This phenomenon was known as remote ischemic preconditioning (RIPC) (15).

Ren et al. demonstrated that hind limb RIPC decreases brain injury after ischemia (18). Another study showed that bilateral femoral arteries RIPC can increase spinal cord tolerance against ischemia in rabbits (6). This study was done to evaluate and compare the effect of hind and fore limbs (unilateral, bilateral, ipsilateral, and contralateral) RIPC as a simple and non-invasive approach to the spinal cord IR injury in rats.

\section{MATERIAL and METHODS}

\section{Animals}

The total of 36 male rats (Sprague-Dawley, 220- $250 \mathrm{gr}$ on the day of surgery) were randomly distributed to the 6 groups: sham surgery (the abdominal aorta was exposed, not limb RIPC and not spinal cord IR), control (only spinal cord IR), unilateral (3 cycles of $4 \mathrm{~min} / 4 \mathrm{~min}$ IR in right hind limb as RIPC, 30 minutes before spinal cord IR), bilateral (3 cycles of $4 \mathrm{~min} / 4$ min IR in right hind limbs as RIPC, 30 minutes before spinal cord IR), ipsilateral ( 3 cycles of $4 \mathrm{~min} / 4 \mathrm{~min} I \mathrm{R}$ in right hind limb and right fore limb as RIPC, 30 minutes before spinal cord $\mathrm{IR}$ ), contralateral (3 cycles of $4 \mathrm{~min} / 4 \mathrm{~min} I R$ in right hind limb and left fore limb as RIPC, 30 minutes before spinal cord IR). This study was approved by the ethics committee of Urmia University of Medical Sciences (Approval No: IR.UMSU. REC.1396.104, date 7 June 2017).

\section{Remote Ischemic Preconditioning (RIPC)}

At first, the rats were anesthetized with ketamine and xylazine (50 mg/kg and $5 \mathrm{mg} / \mathrm{kg}$; i.p., respectively). Then, ischemia was performed on the limb(s) of each rat by a tourniquet (a rubber band) with 3 cycles of 4 minutes of ischemia followed by 4 minutes of reperfusion (26). Circulatory suppression in the limbs was recognized by monitoring the limb skin color, using a pulseoxymeter clip on the paw (6).

\section{Surgical Procedure}

Thirty minutes after limb RIPC, rats were anesthetized with ketamine and xylazine. The body temperature of animals was adjusted to normal $\left(37.5^{\circ} \mathrm{C} \pm 0.5^{\circ} \mathrm{C}\right)$ by using an overhead lamp. According to a previous study (9), the abdominal aorta of rats was exposed. In the sham group, surgery was completed at this stage. In the other experimental groups, surgery was performed using abdominal aortic clamping between the left renal artery and the aortic bifurcation for 60 minutes. Reperfusion was established after ischemia. At the end of the surgery, abdominal wall was sutured. In the animals, the Crede maneuvre was applied to empty the bladder twice a day.

\section{Neurologic Evaluation}

Neurologic evaluation was performed in animals prior to surgery and 72 hours after spinal cord IR. The motor deficit index (MDI) score was determined as the sum of scores from placing/stepping reflex and ambulation. The maximum functional deficiency was indicated with a score of 6 . The rats with $\mathrm{MDI}<3$ and $\mathrm{MDI} \geq 3$ were considered as nonparaplegic, and paraplegics, respectively (22).

\section{Blood Sampling}

After MDI evaluation, the plasma samples were obtained directly from the heart by collecting blood and centrifuging at $1500 \mathrm{~g}\left(15 \mathrm{~min}\right.$ at $\left.4^{\circ} \mathrm{C}\right)$. The samples were stored at $-20^{\circ} \mathrm{C}$ before the analysis of catalase, malondialdehyde (MDA), and total antioxidative capacity (TAC).

\section{Biochemical Measurements}

The plasma analysis of catalase, MDA, TAC were performed in accordance with the kit guides (Zellbio Veltlingrweg 29, 89075 Ulm, Germany). In brief, plasma level of MDA reacted with the thiobarbituric (TBA) reagent, and the pink-colored of plasma was evaluated with spectrophotometrically at $532 \mathrm{~nm}$. Also, the plasma level of TAC was determined based on the response of peroxide / peroxidase. After adding the stop solution, changes the color from pink to yellow and is measured at $450 \mathrm{~nm}$ using spectrophotometrically (28). The plasma level of catalase was measured by spectrophotometrically at $240 \mathrm{~nm}$ (6).

\section{Staining with 2,3,5-Triphenyltetrazolium}

After collecting the blood sample, the fourth lumbar segment was separated, cut thick sections of $1.5-2 \mathrm{~mm}$, and incubated in TTC (Sigma-Aldrich), and then for fixation the specimens were transferred to a buffered formalin (10\%). The district of infarction of spinal cord was photographed in each experimental group.

\section{Histological Evaluation}

After cardiac perfusion (10\% buffered formalin), the fourth lumbar segment of spinal cord was dissected, washed with $0.9 \% \mathrm{NaCl}$, and fixed in the buffered formalin. Then, transverse sections were stained with conventional hematoxylin and eosin (H\&E). The number of normal motor neurons was calculated in the ventral area of the gray matter at 400x (ventral region of the central canal). The normal motor neurons included loose chromatin, Nissle substance in the cytoplasm, and eminent nucleoli (8). Damage caused by white matter in the anterior and anterolateral funiculi was evaluated based on the development of microvacuolation: 0 as normal (without the formation of vacuoles); 1 as mild injury ( $<11 \%$ area affected); 2 as moderate injury (10\% to $50 \%$ ); and 3 as severe injury (>50\%) (12).

\section{Statistical Analysis}

Data were demonstrated as mean \pm SEM. Statistical analysis and calculations were accomplished by SPSS 16.0. ANOVA followed by Tukey's post hoc test for multiple comparisons. Kruskal-Wallis analysis of variance was applied to detect differences of MDI and white matter damage among experimental groups and followed by the Mann-Whitney $U$ test. 


\section{RESULTS}

The mean MDI scores significantly decreased in the ipsilateral $(1.5 \pm 0.7)$, contralateral $(1 \pm 0.0)$, and bilateral $(1.3 \pm 0.67)$ groups than in the unilateral $(2 \pm 0.47)$ group 72 hours after spinal cord IR $(p<0.05)$ (Figure 1).

Plasma level of MDA significantly decreased in the ipsilateral group $(13.1 \pm 0.25 \mathrm{mmol} / \mathrm{L})$ compared with the control group $(15.5 \pm 0.85 \mathrm{mmol} / \mathrm{L})(\mathrm{p}<0.05)$. However, in the contralateral, and bilateral groups, the calculated values were less than those measured in the control group, but the differences were not statistically significant ( $p>0.05$ ) (Figure 2 ).

The plasma level of TAC was significantly increased in the contralateral $(0.69 \pm 0.27 \mathrm{mmol} / \mathrm{L})$, ipsilateral $(0.65 \pm 0.31$ $\mathrm{mmol} / \mathrm{L})$, bilateral $(0.56 \pm 0.2 \mathrm{mmol} / \mathrm{L})$, and unilateral $(0.48$ $\pm 0.14 \mathrm{mmol} / \mathrm{L})$ group compared with control $(0.37 \pm 0.07$ $\mathrm{mmol} / \mathrm{L})$ group $(\mathrm{p}<0.05)$ (Figure 3$)$.

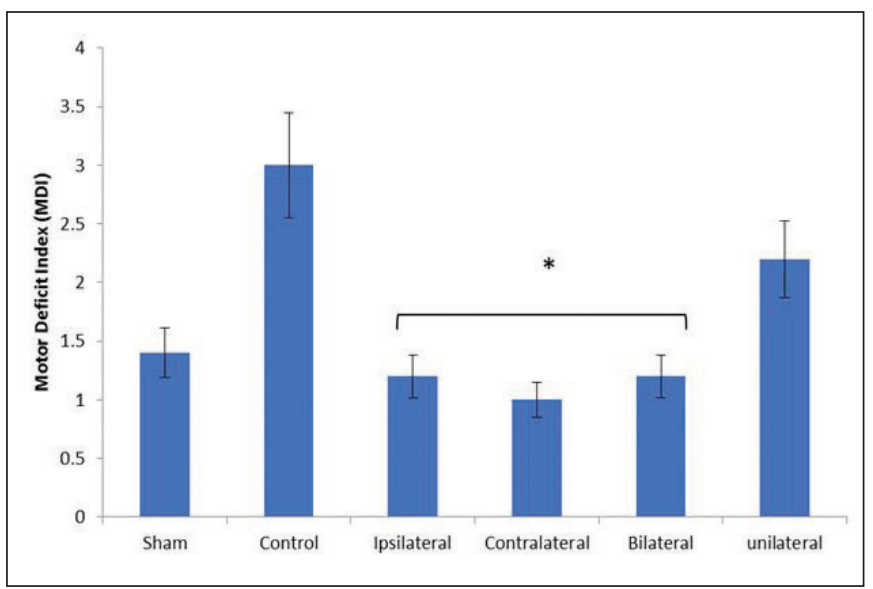

Figure 1: The mean neurological scores determined at 72 hours after spinal cord IR. *: A significant difference ipsilateral, contralateral, and bilateral groups comparison with unilateral group $(p<0.05)$.

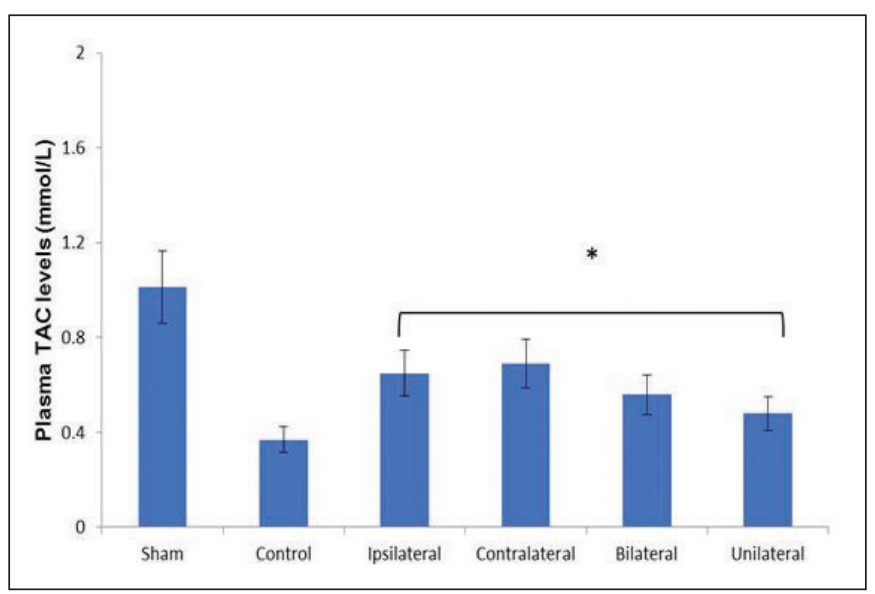

Figure 3: The mean plasma level of TAC determined at 72 hours after spinal cord IR. *: A significant difference contralateral, ipsilateral, bilateral, and unilateral groups in comparison with control group $(p<0.05)$.
The plasma level of catalase was significantly increased in the contralateral $(55.0 \pm 3.43 \mathrm{mmol} / \mathrm{L})$, ipsilateral $(55.8 \pm 0.55$ $\mathrm{mmol} / \mathrm{L})$, and bilateral $(55.4 \pm 0.62 \mathrm{mmol} / \mathrm{L})$ groups compared with control $(49.8 \pm 2.04 \mathrm{mmol} / \mathrm{L})$ group $(\mathrm{p}<0.05)$ (Figure 4$)$.

TTC staining showed the several zones of microinfarction distinguished by peaking regions were remarked in the spinal cord tissue from unilateral and control groups. The microinfarctions were significantly reduced in contralateral, ipsilateral, and bilateral groups (Figure 5A-F).

The mean number of normal motor neurons in the contralateral (81.7 \pm 3.1$)$, ipsilateral $(77.5 \pm 2.16)$, bilateral $(68.9 \pm 5.4)$, and unilateral $(58.5 \pm 5.4)$ groups was more than in control group $(40.25 \pm 3.97)(p<0.05)$. Although approximately $56 \%$ of motor neurons in were lost in control group, only about $9.77 \%$, $13.76 \%, 23.42 \%$, and $35.11 \%$ were lost in contralateral, ipsilateral, bilateral, and unilateral groups, respectively (Figure $6 A, B)$.

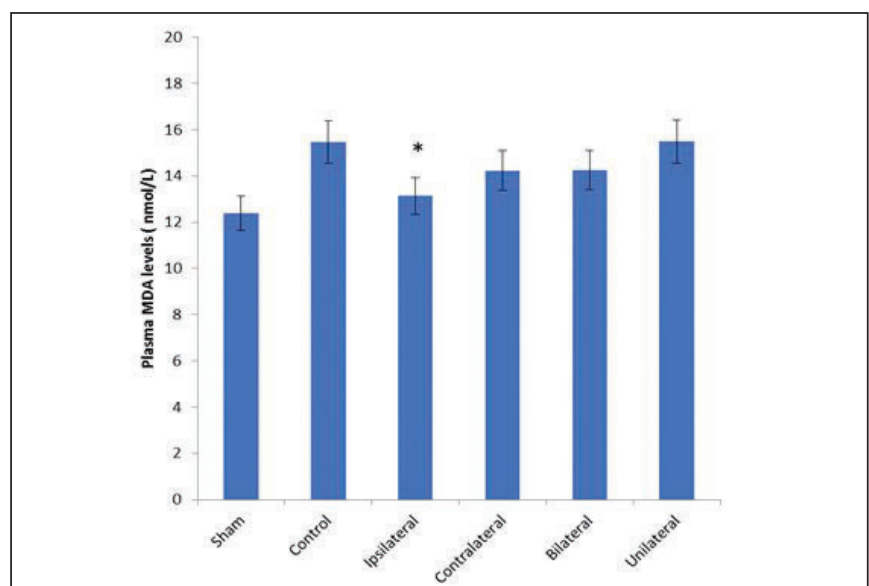

Figure 2: The mean plasma level of Malondialdehyde (MDA) determined at 72 hours after spinal cord IR. *: A significant difference ipsilateral group in comparison with control group $(p<0.05)$.

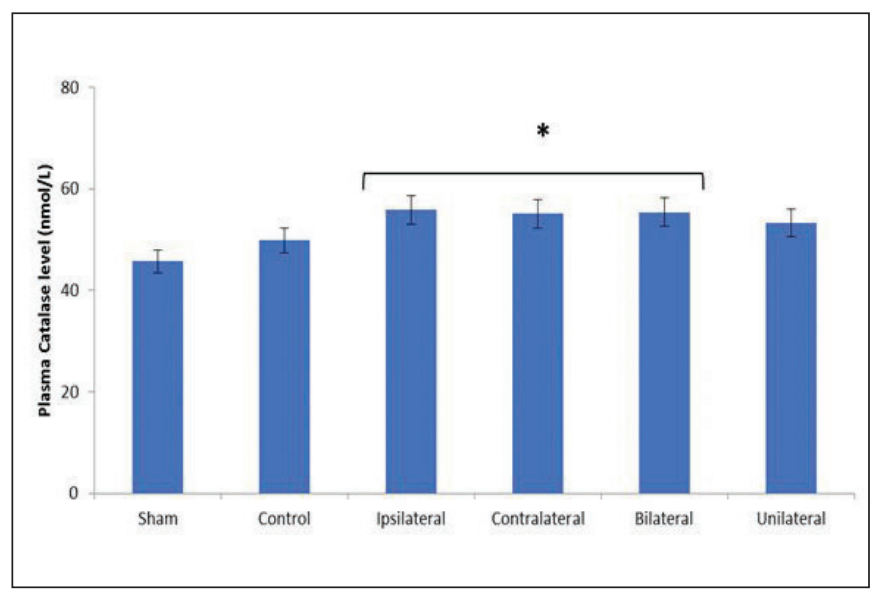

Figure 4: The mean plasma level of catalase determined at 72 hours after spinal cord IR. *: A significant difference contralateral, ipsilateral, bilateral groups in comparison with control group $(p<0.05)$. 

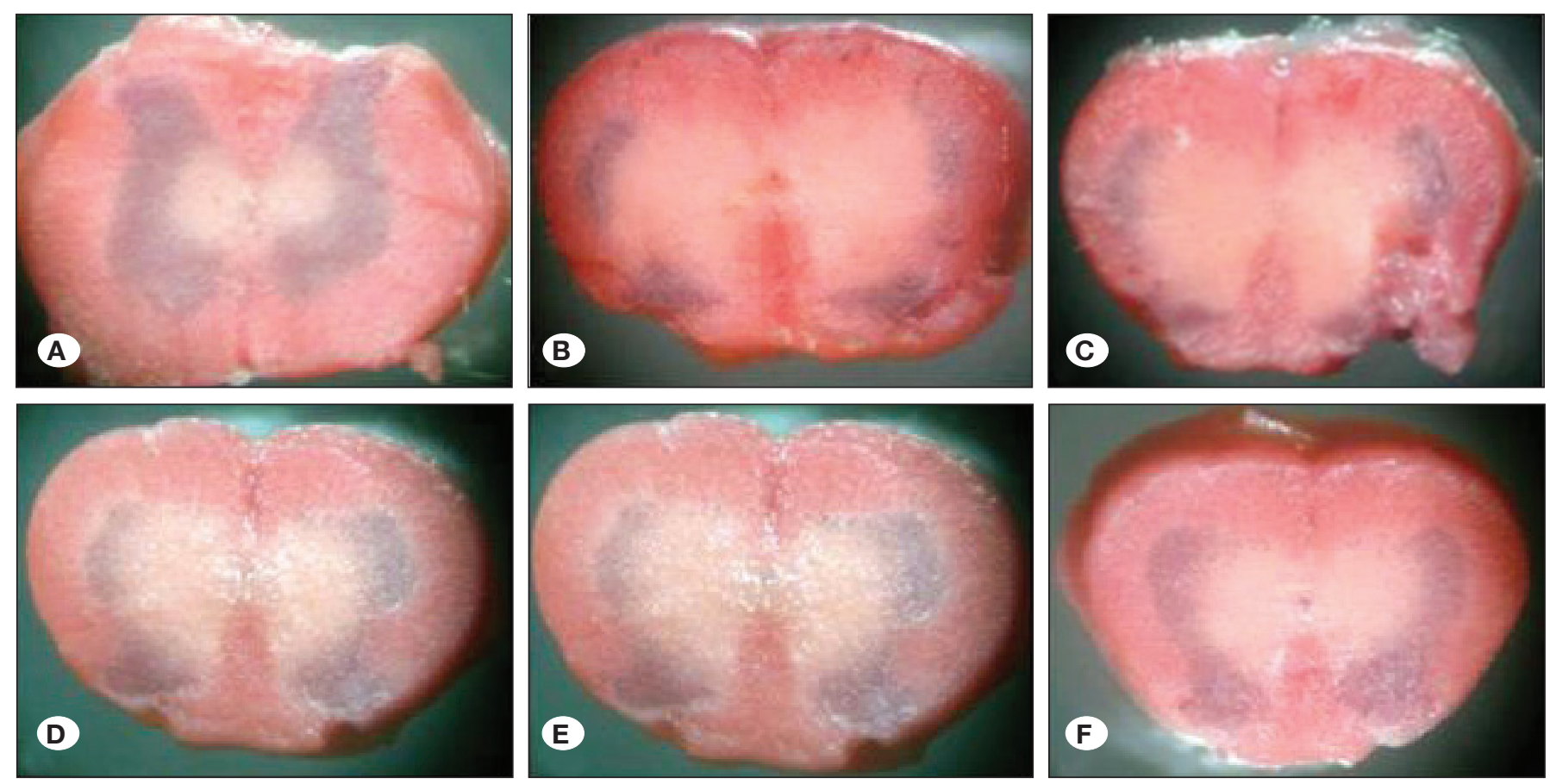

Figure 5: Spinal cord ischemia revealed by triphenyltetrazolium chloride (TTC) staining 72 hours after ischemia in the sham surgery group (A), control group (B), unilateral group (C), bilateral group (D), ipsilateral group (E), and contralateral group (F). TTC reacts with dehydrogenases in viable cells and results in a "brick-red" color, and the white area indicates the ischemia.

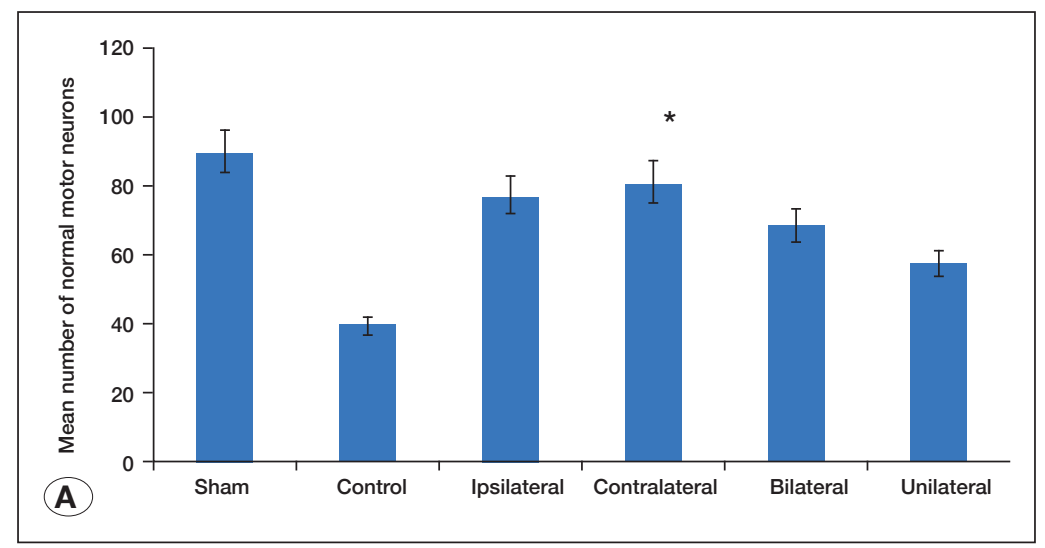

Figure 6: A) The mean number of normal motor neurons in the anterior spinal cord at 72 hours after spinal cord IR. *: A significant difference contralateral, ipsilateral, bilateral, and unilateral groups in comparison with control group $(p<0.05)$. B) Representative light microphotographs of the anterior horn of spinal cord at 72 hours after IR in the sham surgery (a), control (b), unilateral (c), and bilateral (d), (e) ipsilateral, (f) contralateral groups. Shrunken neurons contained dark hyperchromatic nuclei and Nissl granules had disappeared, were shown (arrow) (Hematoxylin and Eosin; Scale bar $=40 \mu \mathrm{m}$ ).

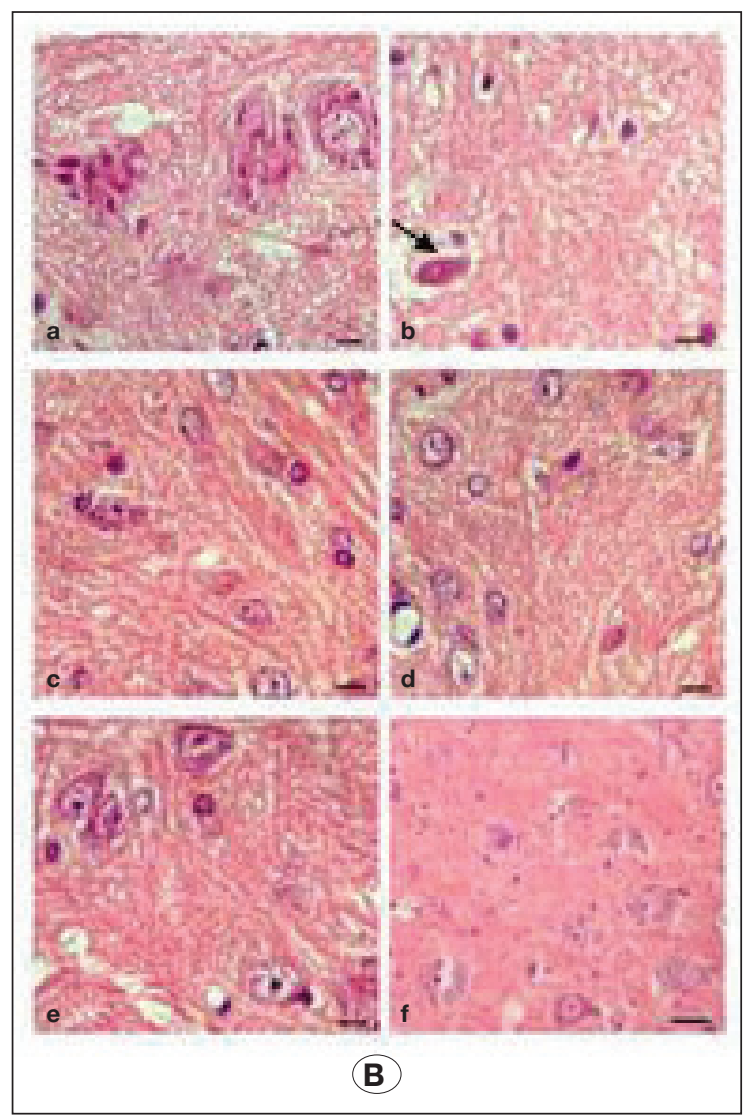


The mean scores for white matter damage in the contralateral $(1.25 \pm 0.50)$, unilateral $(1.50 \pm 0.57)$, and bilateral (1.5.1 $\pm 0.47)$ groups were less than control group $(2.50 \pm 0.57)$ $(p<0.05)$. There was no difference in mean score for white matter damage in the ipsilateral $(1.75 \pm 0.50)$ compared with control groups ( $p>0.05$ ) (Figure 7A, B).

\section{DISCUSSION}

The results of our study indicated that the rats in contralateral, bilateral, and ipsilateral limbs RIPC groups had a better hind limb motor function, and lower spinal cord tissue damage white 72 hours after spinal cord IR. Based on our information, this study seems to be the first report to describe the advantageous effects of contralateral, ipsilateral, and bilateral limbs RIPC on IR of spinal cord in rats.

This study results are in agreement with those reported in previous studies that RIPC protects IR injury of the heart (2), brain (3), and skeletal muscles (17). A previous study has indicated that kidney RIPC can enforce ischemic tolerance in the spinal cord in rabbit (10). However, it seems that the use of the short ischemic cycle on kidney or any other vital organ before spinal cord IR seems to be harmful and impractical (20).

The results of our study confirm the results of previous study that 3 cycles of the femoral artery occlusion (RIPC) can increase spinal cord tolerance over long-term ischemia. It has been showed that RIPC reduces MDI and increases the normal motor neurons (20). On other hand, Dong et al. have shown that 2 RIPC cycles (bilateral femoral arteries; occlusion 10 minutes/ reperfusion 10 minutes) can protect the spinal cord against ischemia for 20 minutes in the rabbit (6). In addition, Weinbrenner et al. showed that the effect of a long time of RIPC cycle on abdominal aorta in the heart ischemia is more effective than multiple brief cycles of IR (27). However, obstruction of the femoral and abdominal arteries in RIPC stage is unsafe and invasive compared to clamp of limbs. Also, increasing the duration of occlusion /reperfusion in cycles may cause restlessness and discomfort in the patients.

This is a surprising study that contralateral, bilateral, and ipsilateral limb RIPC can protect spinal cord ischemia for 60 minutes, while in previous studies the maximum duration of spinal cord ischemic was 20 minutes $(6,20)$. The duration of aortic cross-clamping is an effective factor in increasing the rate of postoperative paraplegia. However, the rate of paraplegia increases from $0 \%$ (when the aortic cross-clamp time is less than 15 minutes) to $25-100 \%$ (when the time exceeds 60 minutes) (21).

In this study, the reduction in mean MDI scores may indicate a protective effect of RIPC. A previous study suggested that biochemical and histological evaluations cannot completely reflect variations in rat limb functions (7), therefore functional assessment is main objective index in recovery judgment after surgery (11).

This study has shown that at least one part of the neuroporotecive effect of limb RIPC in spinal cord IR is due

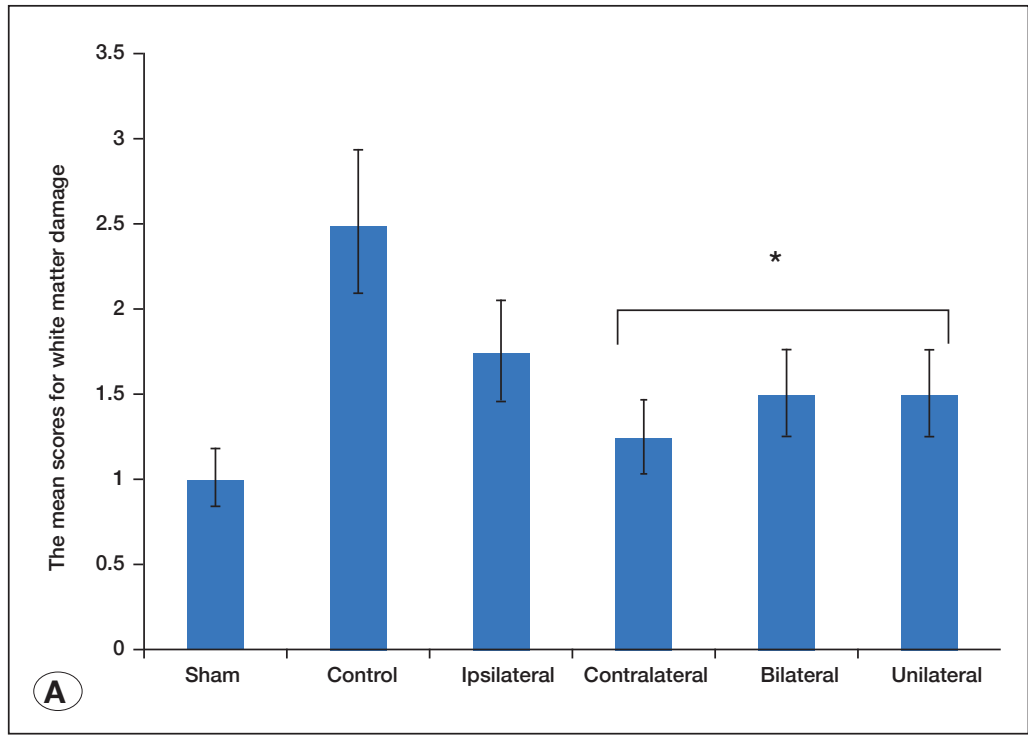

Figure 7: A) The mean scores for white matter damage in the anterior and lateral funiculi of spinal cord at 72 hours after spinal cord IR.

*: A significant difference contralateral, bilateral, and unilateral groups in comparison with control group $(p<0.05)$. B) Representative light microphotographs of the anterior and lateral funiculi of spinal cord at 72 hours after IR in the sham surgery (a), control (b), unilateral (c), and bilateral (d), (e) ipsilateral, (f) contralateral groups (Hematoxylin and Eosin; Scale bar $=40 \mu \mathrm{m})$.

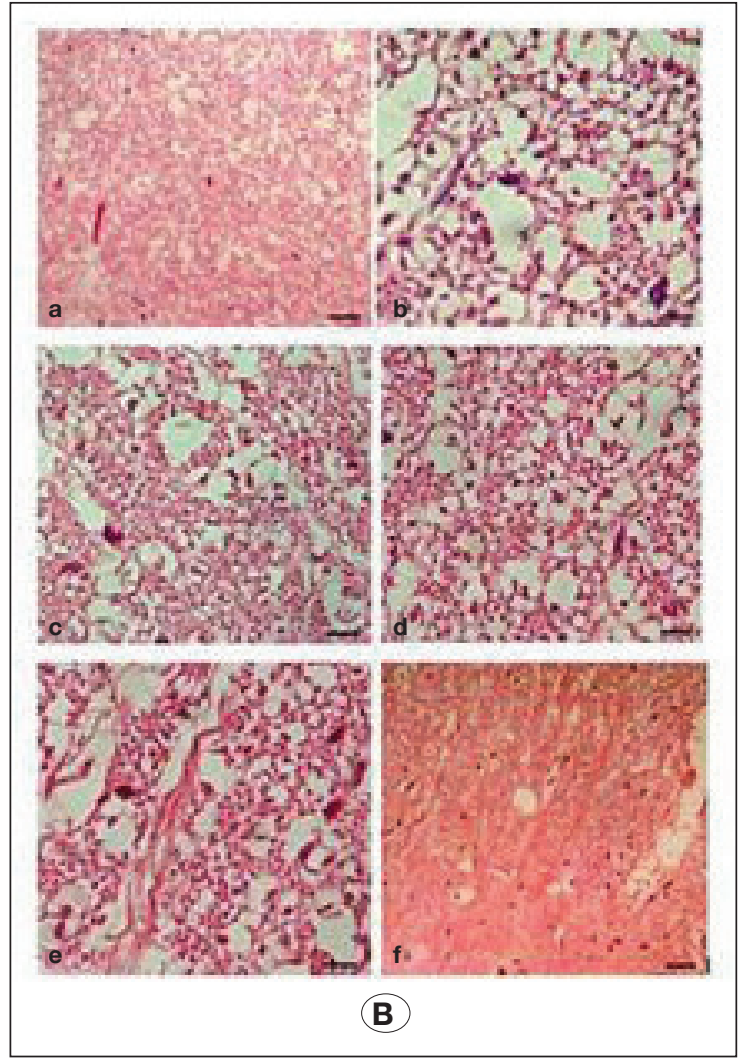


to its antioxidant activity. So that, plasma levels of TAC and catalase were significantly increased in experimental groups in comparison with the control groups. Obtained confirm the results of the previous study, that RIPC increases the amount of antioxidants (catalase and SOD) in the serum (6). In addition, also it wasfound that plasma level of MDA in limb RIPC groups was lower than those measured in the unilateral and control groups.

In this study, catalase and the numbers of normal motor neurons in the experimental groups were more than unilateral and control groups. It is indicated that the obtained results are in agreement with previous study that occlusion of both hind limbs is more effective than one. Its protective effect may be conditionally upon the volume of the remote tissue/organ (26).

In confirmation of previous studies $(6,20)$, the results of our study show that the mean numbers of normal motor neurons in the limb RIPC groups were more than in the control group. Also, the white matter damage score in the experimental groups was decreased compared with the control group. It seems that limb RIPC prevented histologic changes, such as microinfarction in the white matter and loss of motor neuron cells in spinal cord. In this study, neurological assessment confirmed the histologically findings. The limb RIPC may stimulate the spinal cord tissue to adjust to a future ischemic occurrence (18). In addition, the previous study shows that limb RIPC are associated with the antiapoptotic proteins such as $\mathrm{Bcl}-\mathrm{XL}$ and $\mathrm{Bcl}-2$, and they promote cell survival (29).

The previous study emphasized that occlusion of the bilateral femoral arteries significantly reduces the spinal cord infarction volume (6). There is a hypothesis that infarct size lonely does not reflect the protective effect of a neuroprotetive material (18). Some mechanisms that describe the effect of the RIPC on the reducing the infarct size including the actions of purine nucleoside (adenosine), and mitochondrial channel closure and openness (29).

A previous study suggested that humoral mediator like oxygen-free radicals induced by limb RIPC are more effective in increasing spinal cord tolerance against ischemia $(6,26)$. In this study, neurological, biochemical, and histoligical assessments show that contralateral, ipsilateral, and bilateral limb RIPC groups were better than unilateral group. So that the tolerance of organ or tissue through RIPC (13). Dong et al. indicated that production of adenosine increases both in blood circulation and in the spinal cord after RIPC. Increasing adenosine causes scavenge the reactive oxygen species (ROS) and protects spinal cord (6). Also, ROS produced by leukocytes, and muscle cells may have anti-inflammatory effects (19). In addition, RIPC may change the expression of the inflammatory gene in the leukocytes (14).

In this study, the mean score for damage from white matter in experimental groups was decreased than compared to the control group. One of the reasons for increasing ischemia in the spinal cord tolerance may be due to an increase in levels of prostaglandin I2 in the RIPC (20). Furthermore, an increased in the cellular level of endocannabinoids may also be effective (20).
Although, previous studies investigated the effect of RIPC after 48 hours after reperfusion $(6,20)$, We studied the RIPC effect in 72 hours after reperfusion. This is a limitation in our study. So that necrosis and apoptosis of the spinal cord neurons may occur between 1 and 21 days after surgery (4).

This study has been reviewed in animal sample. Since the limb RIPC is a safe and non-invasive method and it seems that damage to spinal cord neurons along the clamp of the aortic artery is reduced, the use of this method may be useful in the clinic and in human. However, despite the promising positive results of the RIPC, it is impossible to reach the mechanism of noninvasive limb RIPC. In addition, it is not clear that increasing the number and duration of cycles in the RIPC may increase spinal cord protection.

\section{CONCLUSION}

Our study has demonstrated that contralateral, ipsilateral, and bilateral limb RIPC may reduce spinal cord ischemic injury in a rat model.

\section{ACKNOWLEDGEMENTS}

This paper has been extracted from an MSc thesis in the Urmia University of Medical Sciences. Funding for this research project was supported by a grant from Urmia University of Medical Sciences in Urmia, Iran.

\section{REFERENCES}

1. Ali ZA, Callaghan CJ, Lim E, Ali AA, Nouraei SA, Akthar AM, Boyle JR, Varty K, Kharbanda RK, Dutka DP, Gaunt ME: Remote ischemic preconditioning reduces myocardial and renal injury after elective abdominal aortic aneurysm repair: A randomized controlled trial. Circulation 116 Suppl 11:98-105, 2007

2. Andreka G, Vertesaljai M, Szantho G, Font G, Piroth Z, Fontos G, Juhasz ED, Szekely L, Szelid Z, Turner MS, Ashrafian H, Frenneaux MP, Andreka P: Remote ischemic postconditioning protects the heart during acute myocardial infarction in pigs. Heart 93(6):749-752, 2007

3. Arvola $\mathrm{O}$, Haapanen $\mathrm{H}$, Herajärvi J, Anttila T, Puistola $\mathrm{U}$, Karihtala P, Tuominen $\mathrm{H}$, Anttila V: Remote ischemic preconditioning reduces cerebral oxidative stress following hypothermic circulatory arrest in a porcine model. Semin Thorac Cardiovasc Surg 28(1):92-102, 2016

4. Crawford ES, Mizari EM, Hess KR: The impact of aortic perfusion and SSEP monitoring on prevention of paraplegia after aortic operations. J Thorac Cardiovasc Surg 95:356-357, 1988

5. Dobashi K, Singh I, Orak JK, Asayama K, Singh AK: Combination of $\mathrm{N}$-acetylcysteine, sodium nitroprusside and phosphoramidon attenuates ischemia-reperfusion injury in rat kidney. Mol Cell Biochem 240(1-2):9-17, 2000

6. Dong HL, Zhang Y, Su BX, Zhu ZH, Gu QH, Sang HF, Xiong $\mathrm{L}$ : Limb remote ischemic preconditioning protects the spinal cord from ischemia-reperfusion injury: A newly identified nonneuronal but reactive oxygen species-dependent pathway. Anesthesiology 112(4):881-891, 2010 
7. Dong S, Cao Y, Li H, Tian J, Yi C, Sang W: Impact of ischemic preconditioning on ischemia-reperfusion injury of the rat sciatic nerve. Int J Clin Exp Med 8(9):16245-16251, 2015

8. Farjah GH, Mohammad Pour $\mathrm{M}$, Khadem-Ansari $\mathrm{MH}$, Karimipour M, Pourheidar B: Protective effect of aqueous spinach (Spinacia oleracea L.) extract on spinal cord ischemiareperfusion injury in rats. Vet Res Forum 9(2):187-191, 2018

9. Farjah GH, Salehi S, Ansari MH, Pourheidar B: Protective effect of Crocussativus L. (Saffron) extract on spinal cord ischemiareperfusion injury in rats. Iran J Basic Med Sci 20(3):334-337, 2017

10. Gurcun U, Discigil B, Boga M, Ozkisacik E, Badak MI, Yeisey C, Kurtoglu T, Meteoglu I: Is remote preconditioning as effective as direct ischemic preconditioning in preventing spinal cord ischemic injury? J Surg Res 135(2):385-393, 2006

11. Jiang X, Shi E, Nakajima Y, Sato S: Postconditioning, a series of brief interruptions of early reperfusion, prevents neurologic injury after spinal cord ischemia. Ann Surg 244(1):148-153, 2006

12. Kanellopoulos GK, Xu XM, Hsu CY, Lu X, Sundt TM, Kouchoukos NT: White matter injury in spinal cord ischemia: Protection by AMPA/Kainate glutamate receptor antagonism. Stroke 31(8):1945-1952, 2000

13. Khanna G, Diwan V, Singh M, Singh N, Jaggi AS: Reduction of ischemic, pharmacological and remote preconditioning effects by an antioxidant $N$-acetyl cysteine pretreatment in isolated rat heart. Yakugaku Zasshi 94:2193-2200, 2008

14. Konstantinov IE, Arab S, Kharbanda RK, Li J, Cheung MM, Cherepanov V, Downey GP, Liu PP, Cukerman E, Coles JG, Redington AN: The remote ischemic preconditioning stimulus modifies inflammatory gene expression in humans. Physiol Genomics 19(1):143-150, 2004

15. Lazaris AM, Maheras AN, Vasdekis SN, Karkaletsis KG, Charalambopoulos A, Kakisis JD, Martikos G, Patapis P, Giamarellos-Bourboulis EJ, Karatzas GM, Liakakos TD: Protective effect of remote ischemic preconditioning in renal ischemia/reperfusion injury, in a model of thoracoabdominal aorta approach. J Surg Res 154(2):267-273, 2009

16. Mohammad Pour M, Farjah GHH, Karimipour M, Pourheidar $\mathrm{B}$, Khadem Ansari $\mathrm{MH}$ : Protective effect of lutein on spinal cord ischemia-reperfusion injury in rats. Iran J Basic Med Sci 22:412-417, 2019

17. Moses MA, Addison PD, Neligan PC, Ashrafpour H, Huang N, Zair M, Rassuli A, Forrest CR, Grover GJ, Pang CY: Mitochondrial KATP channels in hindlimb remote ischemic preconditioning of skeletal muscle against infarction. Am J Physiol Heart Circ Physiol 288(2):H559-567, 2005
18. Ren C, Gao X, Steinberg G, Zhao H: Limb remotepreconditioning protects against focal ischemia in rats and contradicts the dogma of the therapeutic time windows for preconditioning. Neuroscience 151(4):1099-1103, 2007

19. Souza Filho MV, Loiola RT, Rocha EL, Simão AF, Gomes AS, Souza MH, Ribeiro RA: Hind limb ischemic preconditioning induces an anti-inflammatory response by remote organs in rats. Braz J Med Biol Res 42(10):921-929, 2009

20. Su B, Dong H, Ma R, Zhang X, Ding Q, Xiong L: Cannabinoid 1 receptor mediation of spinal cord ischemic tolerance induced by limb remote ischemia preconditioning in rats. J Thorac Cardiovasc Surg 138(6):1409-1416, 2009

21. Svensson LG, Crawford ES, Hess MS, Coselli JS, Safi HJ: Experience with 1509 patients undergoing thoracoabdominal aortic operations. J Vas Surg 17:357-368, 1993

22. Taira Y, Marsala M: Effect of proximal arterial perfusion pressure on function, spinal cord blood flow, and histopathologic changes after increasing intervals of aortic occlusion in the rat. Stroke 27:1850-1858, 1996

23. Tapuria N, Kumar Y, Habib MM, Abu AM, Seifalian AM, Davidson BR: Remote ischemic preconditioning: A novel protective method from ischemia reperfusion injury - a review. J Surg Res 150:304-330, 2008

24. Walsh SR, Tang T, Sadat U, Dutka DP, Gaunt ME: Cardioprotection by remote ischaemic preconditioning. $\mathrm{Br} \mathrm{J}$ Anaesth 99:611-616, 2007

25. Wan IY, Angelini GD, Bryan AJ, Ryder I, Underwood MJ: Prevention of spinal cord ischemia during descending thoracic and thoracoabdominal aortic surgery. Eur J Cardiothorac Surg 19:203-213, 2001

26. Wever KE, Masereeuw R, Wagener FA, Verweij VG, Peters JG, Pertijs JC, Van der Vliet JA, Warlé MC, Rongen GA: Humoral signaling compounds in remote ischaemic preconditioning of the kidney, a role for the opioid receptor. Nephrol Dial Transplant 28(7):1721-1732, 2013

27. Weinbrenner C, Nelles M, Herzog N, Sárváry L, Strasser $\mathrm{RH}$ : Remote preconditioning by infrarenal occlusion of the aorta protects the heart from infarction: A newly identified non-neuronal but PKC-dependent pathway. Cardiovasc Res 55(3):590-601, 2002

28. Yagi K: Assay for blood plasma or serum. Methods Enzymol 105:328-331, 1984

29. Zhu SB, Liu Y, Zhu Y, Yin GL, Wang RP, Zhang Y, Zhu J, Jiang $W$ : Remote preconditioning, preconditioning, and postconditioning: A comparative study of their cardioprotective properties in rat models. Clinics (Sao Paulo) 68(2):263-268, 2013 